\title{
Participação de indígenas Terena na resistência à emancipação da tutela durante a ditadura militar ${ }^{1}$ Participation of Terenas in the resistance to the emancipation of the tutelage during the military dictatorship
}

\author{
Victor Ferri Mauro²
}

DOI: http://dx.doi.org/10.20435/tellus.v19i39.608

\begin{abstract}
Resumo: Com base em referências bibliográficas e documentais, analisamos um momento histórico em que os governos de Ernesto Geisel (1974-1979) e João Batista Figueiredo (1979-1985) cogitaram emancipar da tutela prevista pela Lei 6.001/73 os povos indígenas que consideravam "integrados à comunhão nacional". Nesse contexto, o povo Terena e alguns de seus membros eram citados pelas autoridades oficiais como exemplos de "índios emancipáveis". Essa proposta sofreu uma forte reação do movimento indígena, de entidades da sociedade civil e de outros aliados da causa, por se temer o risco de os povos originários serem subtraídos em seus direitos diferenciados, sobretudo no que tange às garantias territoriais. Amparada em um dispositivo da mencionada lei, a Fundação Nacional do Índio (FUNAI) contratou vários indígenas como funcionários e posteriormente os pressionou a pedirem sua emancipação individual. Porém, nenhum desses servidores chegou a se emancipar. Alguns Terena também tiveram uma participação destacada na criação das primeiras associações de representação indígena em nível nacional, que chegaram a ser boicotadas pelo Estado. Devido à repercussão negativa na opinião pública, o projeto de emancipação foi abandonado e, com a promulgação da Constituição de 1988, a tutela perdeu o seu sentido mais restritivo, permanecendo apenas o sentido de proteção especial.
\end{abstract}

Palavras-chave: Terena; emancipação; resistência.

Abstract: Based on bibliographical and documentary references, we analyzed a historical moment in which the governments of Ernesto Geisel (19741979) and João Batista Figueiredo (1979-1985) considered emancipating the tutelage required by Law 6,001/73 indigenous peoples that they considered "integrated to the national communion". In this context, the Terena people

1 Uma versão preliminar deste artigo foi apresentada na 31a Reunião Brasileira de Antropologia, realizada entre os dias 9 e 12 de dezembro de 2018, em Brasília, DF.

2 Universidade Federal de Mato Grosso do Sul (UFMS), Campo Grande, Mato Grosso do Sul, Brasil. 
and some of its members were cited by the official authorities as examples of "emancipable Indians". This proposal has suffered a strong reaction from the Indigenous Movement, from civil society entities and from other allies of the cause, as there is a risk that indigenous peoples will be deprived of their specific rights, especially as regards territorial guarantees. Supported by a provision of the aforementioned law, National Indian Foundation (FUNAI) hired several natives as officials and subsequently pressured them to ask for their individual emancipation. However, none of these servers ever came to be emancipated. Some Terena also had a prominent participation in the creation of the first associations of indigenous representation at the national level, which were later boycotted by the state. Due to the negative repercussion in public opinion, the emancipation project was abandoned and, with the promulgation of the 1988 Constitution, the tutelage lost its restrictive character, remaining only the sense of special protection.

Keywords: Terena; emancipation; resistence.

\section{INTRODUÇÃO}

Acontecimentos das décadas de 1970 e 1980 são considerados fundamentais para a organização e consolidação do movimento indígena em âmbito nacional. Um dos mais importantes foi a resistência dos povos originários a um projeto do governo de emancipar da tutela vários indivíduos e grupos inteiros.

Nos discursos de autoridades oficiais, os Terena eram frequentemente citados como exemplo de índios que poderiam ser emancipados por terem alcançado um avançado grau de integração à comunhão nacional e por supostamente viverem de forma indistinta aos demais brasileiros. Também se falou em priorizar a emancipação de indivíduos considerados mais preparados para exercer sua cidadania sem a intermediação do órgão tutor, aparecendo com frequência nesses discursos sempre algum Terena com projeção.

A proposta governamental, no entanto, não foi bem acolhida pelos indígenas e pelas organizações da sociedade civil que Ihes prestavam apoio, principalmente porque havia a desconfiança de que a posse sobre as terras tradicionalmente ocupadas poderia não mais estar assegurada às coletividades a partir do ato emancipatório.

Depois de muita articulação política e resistência dos índios, o projeto foi abandonado, até que a nova Constituição derrubou o paradigma integracionista, reconhecendo o direito de as etnias conservarem seus usos, costumes e tradições. 
Com isso, o Estado não pode mais utilizar da prerrogativa da tutela para controlar a vida particular dos indígenas, nem pode pressionar para que grupos e indivíduos abdiquem de garantias especiais para gozar da cidadania brasileira plena.

Achamos importante pôr em relevo o fato de que alguns personagens de destaque na luta contra a emancipação vieram a ingressar no quadro permanente de funcionários da Fundação Nacional do Índio (FUNAI).

Embora os Terena fossem os índios mais recorrentemente citados como emancipáveis, não eram os únicos. Diversos indígenas de outras etnias também tiveram papel destacado na resistência contra a emancipação, porém, tivemos que optar por um recorte étnico dada a limitação do espaço para tratar do assunto.

As informações aqui expostas são baseadas principalmente em fontes bibliográficas e notícias da imprensa.

\section{A REPRESENTAÇÃO DOS TERENA NO IMAGINÁRIO OFICIAL}

Na literatura histórica, os Terena gozam da fama de índios laboriosos e colaborativos com a sociedade envolvente. Segundo Carvalho (1979, p. 123), fontes do período pré-colonial informam que antepassados desse grupo "chegaram a atingir nível de produção que os distinguia dos demais grupos nativos, dada a excepcionalidade de seus cultivos agrícolas, de seu artesanato e de sua tecelagem".

Estes nativos "comercializavam, desde a segunda metade do século XVIII, alimentos diversos, tecidos, redes e outros produtos nos estabelecimentos oficiais da Colônia e depois do Império. Por vezes chegaram a estabelecer relações de aliança com os luso-brasileiros" (EREMITES DE OLIVEIRA; PEREIRA, 2007, p. 9).

A tradição de firmar pactos com os não índios resultou no engajamento na guerra contra o Paraguai (1864-1870), na expectativa de que o governo brasileiro, em reconhecimento ao seu patriotismo, assegurasse-Ihes o domínio deles sobre as terras que tradicionalmente ocupavam, o que não aconteceu. Terminada a guerra, aldeias estavam destruídas e a população indígena se dispersou por fazendas da região, que absorveram mão de obra nativa em condições de semiescravidão. No início do século XX, muitos Terena atuaram na construção das linhas telegráficas e na abertura da Estrada de Ferro Noroeste do Brasil (CARVALHO, 1992). 
No século XX, apesar de as terras sob o controle dos Terena serem exíguas, o seu engajamento na agricultura e na pecuária se destacava sob a tutela do Serviço de Proteção aos Índios (SPI). Assim,

[...] o SPI identifica a propensão dos Terena para a assimilação, manifestada na facilidade e habilidade em incorporar novas tecnologias e formas organizacionais. Os Terena passam a ser vistos inclusive como aliados estratégicos na tentativa de atingir outras populações indígenas consideradas como mais refratárias aos objetivos integracionistas do órgão indigenista. (PEREIRA, 2009, p. 119).

Lembrando um episódio que ocorreu em 1922, quando um líder Terena redigiu um documento ao SPI reivindicando a substituição dos funcionários "brancos" por indígenas, Vargas (2011, p. 387) ressalta que, já naquela época, "os Terena se reconheciam como capazes de se administrarem. Apropriando-se das normas que regiam o SPI julgaram-se habilitados para as tarefas administrativas daquele órgão".

Nas primeiras décadas daquele século, o SPI atraiu famílias Terena para viverem na reserva indígena de Dourados, na esperança de que motivassem o incremento da lavoura de outros povos (CARDOSO DE OLIVEIRA, 1976), pois acreditava-se que a interação com as etnias Kaiowá e Nhandeva e a miscigenação que dela resultaria propiciariam a civilização gradual dessa população (PEREIRA, 2009).

Em 1932, famílias terena começaram a migrar para a reserva indígena de Araribá, no noroeste paulista, também estimuladas pela agência estatal (DINIZ, 1979). Esperava-se que os recém-chegados disseminassem conhecimentos agrícolas e artesanais aos Kaingang e Guarani (CARVALHO, 1979).

O trabalho externo às aldeias em Mato Grosso absorvia grande contingente. Em meados dos anos 1940, "a quase totalidade dos estabelecimentos pecuários vizinhos empregavam os próprios Terena como trabalhadores, fosse como diaristas ou como trabalhadores fixos (peões)" (AZANHA, 2005, p. 84). O tipo de empreitada "ia desde a derrubada da mata e a formação das pastagens e lavouras até à manutenção, plantio das roças, manejo do gado, além da construção da infra-estrutura das propriedades" (XIMENES, 2011, p. 74).

A massiva conversão ao cristianismo foi outro fator que chamou a atenção para a percepção dos Terena como um povo que buscava aproximação com os ditos civilizados. No final dos anos 1960, Schaden (1969, p. 237) verificava que 
Missionários norte-americanos, tanto católicos como protestantes, que há muitos decênios envidam esforços sistemáticos e altamente competitivos para conduzir os Terêna cada qual para a sua respectiva confissão, lograram fazer com que todos ou quase todos os membros da tribo se considerem hoje membros de uma ou de outra Igreja.

Tempos mais tarde, Darcy Ribeiro (1986, p. 409) fez o seguinte comentário:

Dentre todos os índios civilizados que conhecemos, os Terena são os únicos que chegaram a experimentar uma efetiva conversão religiosa. Com efeito, a conduta dos Terena protestantes, tanto no culto como na vida diária, é quase indistinguível da de qualquer população rural pobre.

Quanto às relações com a cidade, na década de 1960, Cardoso de Oliveira (1968, p. 125) já constatava que

Não há Terêna adulto que não tenha, de um modo ou de outro, alguma experiência relacionada com a vida urbana. Ou por passagens pelas cidades da região proporcionada por labour migration, ou por viagens de uma aldeia a outra em busca de novas moradas de caráter permanente, ou, ainda, se bem que em menor número, por excursões recreativas e esportivas, o índio participa naquelas pautas culturais mais atraentes da vida citadina. Essas diferentes modalidades de contato com a cidade conduz o Terêna aldeado a acolher, gradativa e progressivamente, um expressivo número de idéias, capaz de reorienta-lo na situação interétnica e, de um modo muito particular, na situação de vida comunitária na reserva.

A interação com os agrupamentos urbanos fez aumentar a necessidade de renda para adquirir bens e serviços não produzidos nas comunidades e, assim, os trabalhos assalariados foram ganhando importância, sendo os cargos públicos o tipo de emprego mais cobiçado, por conferir certa estabilidade.

Conforme identificou Pereira (2009), os Terena costumam apresentar um estilo de comportamento peculiar nos relacionamentos com instituições e com membros da sociedade envolvente, o qual preconiza a demonstração de civilidade principalmente com aqueles que ocupam posições de prestígio. Esse código de etiqueta "envolve palavras, atos e formalidades reciprocamente adotadas para demonstrar respeito mútuo e consideração, de acordo com o status atribuído a cada posição social” (PEREIRA, 2009, p. 84).

A forma diplomática e polida de encaminhar reivindicações contribui para que os Terena sejam pensados pelos agentes governamentais como índios mais 
"aculturados" que a maioria. Isto posto,

[...] a representação social, que circulava no SPI acerca dos índios Terena, de que estes índios seriam mais 'civilizados', mais 'capazes' para o trabalho, levou também a considerá-los como próximos da 'emancipação', ou seja, da retirada de suas aldeias da estrutura político-administrativa do SPI. (FERREIRA, 2007, p. 138).

Tal percepção se aprofundou após a criação da FUNAI em 1967.

\section{TUTELA E CAPACIDADE CIVIL NO ESTATUTO DO ÍNDIO}

Tendo nascido em pleno regime militar para substituir o SPI na gestão da política indigenista, a FUNAI

[...] foi criada sob a premissa do relacionamento desigual entre o indígena e o Estado. A instituição tratou o indígena, oficialmente, como um ser passivo e primitivo que dependia da tutela estatal não só para sobreviver, também para se desenvolver "corretamente". (TRINIDAD, 2018, p. 275).

Com a exceção de curtos períodos, o comando dessa autarquia esteve com oficiais de alta patente até julho de 1983. Havia uma percepção dos governantes de que a assistência aos indígenas gerava despesas excessivas e inviabilizava a exploração por particulares das riquezas contidas nas áreas sob controle dos grupos. Nesse sentido, interessava retirar progressivamente investimentos públicos nas comunidades e abolir o caráter inalienável de suas terras, promovendo a aceleração da incorporação destas à economia de mercado.

O principal marco regulatório da política de assistência e proteção aos indígenas passou a ser a Lei 6.001, conhecida como Estatuto do Índio, promulgada em 1973. Tal diploma legal, em seu artigo primeiro, declarava como objetivo integrar os índios "progressiva e harmoniosamente, à comunhão nacional" (BRASIL, 1973, n.p.).

Influenciado por uma concepção evolucionista de cultura, o artigo quarto dessa legislação classificava os indígenas em três categorias, de acordo com o seu grau de integração na nação brasileira:

I- Isolados - Quando vivem em grupos desconhecidos ou de que se possuem poucos e vagos informes através de contatos eventuais com elementos da comunhão nacional; 
II- Em vias de integração - Quando, em contato intermitente ou permanente com grupos estranhos, conservam menor ou maior parte das condições de sua vida nativa, mas aceitam algumas práticas e modos de existência comuns aos demais setores da comunhão nacional, da qual vão necessitando cada vez mais para o próprio sustento;

III- Integrados - Quando incorporados à comunhão nacional e reconhecidos no pleno exercício dos direitos civis, ainda que conservem usos, costumes e tradições característicos da sua cultura. (BRASIL, 1973, n.p.).

Observando a categorização acima exposta, fica fácil de compreender que O arcabouço ideológico que embasou a construção do Estatuto do Índio, em 1973, estava atrelado à ideologia integracionista, entendendo a condição de indígena como algo transitório, considerando que o índio, na medida em que conhecesse a "civilização", dela se embeberia, se transformando em um civilizado e deixando, por isso, de ser índio - perdendo, consequentemente, seus direitos diferenciados. (MENEZES, 2016, p. 526).

Os índios considerados não-integrados ficavam subordinados à tutela da FUNAI para proteção de seu patrimônio. De acordo com Marczynski (1991), o Código Civil de 1916 - somente revogado em 2002 -, em seu art. 6o, imputava sobre os indígenas uma tutela que não os reconhecia como sujeitos de capacidade civil plena. Esse instrumento compreendia que o índio "está culturalmente diminuído para entender, querer e manifestar o que quer conforme as normas sociais e os preceitos legais da sociedade nacional" (MARCZYNSKI, 1991, p. 324).

Conforme a leitura de Martins (2005, p. 89),

Entendeu o legislador civil daquela época que, da mesma forma que os menores, entre 16 e 21 anos, ou os pródigos, os índios não possuem uma visão aprimorada da sociedade envolvente, devendo, por essa razão, estar assistidos nos atos jurídicos, de maneira a evitar prejuízo a eles mesmos, pois assim estariam protegidos da ganância de homens inescrupulosos que poderiam se aproveitar de sua ingenuidade.

Naquele momento, a legislação nacional não encampava a figura da propriedade coletiva da terra, e, deste modo, a tutela visava acima de tudo à proteção dos territórios indígenas, sendo o instrumento que garantia aos índios o "usufruto permanente e exclusivo de suas terras e recursos naturais do solo" (RAMOS, 2011, p. 68). Nesses termos, faz sentido pensar que "Embora o conceito de tutela sobre populações indígenas pareça no mínimo paternalista e 
anacrônico, na prática, deu-lhes uma proteção jurídica eficaz" (CUNHA; ALMEIDA, 2009, p. 280).

Conforme Amado (2016, p. 262), em relatos de caciques hoje idosos, é recorrente "a lembrança dos tempos em que até para viajarem necessitavam de uma autorização da FUNAI, sem a qual não poderiam nem sair da comunidade".

O teor do artigo oitavo do Estatuto deixa transparecer o forte controle governamental sobre os tutelados:

Art. 8 São nulos os atos praticados entre o índio não integrado e qualquer pessoa estranha à comunidade indígena quando não tenha havido assistência do órgão tutelar competente.

Parágrafo único. Não se aplica a regra deste artigo no caso em que o índio revele consciência e conhecimento do ato praticado, desde que não lhe seja prejudicial, e da extensão dos seus efeitos. (BRASIL, 1973, n.p.).

Esses termos explicitam a inviabilidade de o indígena "firmar qualquer tipo de contrato (compra, venda, abrir conta em banco, etc.) sem a assistência do órgão tutelar (FUNAI) sob pena de nulidade" (AMADO, 2016, p. 263).

O professor Silvio Coelho dos Santos entendia que a tutela prevista no Estatuto não vinha sendo interpretada corretamente por servidores públicos que a administravam, pois, no seu sentido lato, ela significava uma proteção especial que, na prática, não impedia os indígenas de exercerem a cidadania, pois

Os índios são brasileiros natos; têm direitos políticos, podendo votar e ser eleitos (Resolução 7.019/1966 do Tribunal Superior Eleitoral); têm direito à propriedade (Estatuto do Índio, art. 32); direito a administrarem seus próprios negócios e participarem da administração do patrimônio indígena que é gerido pela Funai (Estatuto do Índio, art. 42); têm direito a se organizarem em associações; têm direito de constituir diretamente advogados (Estatuto do Índio, art. 37). (SANTOS, 1995, p. 98-9).

O Estatuto permitia aos indivíduos interessados a possibilidade de requererem a emancipação dessa tutela a um juiz competente, desde que os solicitantes preenchessem os requisitos estipulados no art. 9o, que eram "I- idade mínima de 21 anos; II- conhecimento da língua portuguesa; III- habilitação para o exercício de atividade útil, na comunhão nacional; IV - razoável compreensão dos usos e costumes da comunhão nacional" (BRASIL, 1973, n.p.). A mesma lei também 
previa a possibilidade de uma emancipação coletiva, desde que solicitada por integrantes do grupo interessado. O artigo 11 estipulava:

Mediante decreto do Presidente da República, poderá ser declarada a emancipação da comunidade indígena e de seus membros, quanto ao regime tutelar estabelecido em lei, desde que requerida pela maioria dos membros do grupo e comprovada, em inquérito realizado pelo órgão federal competente, a sua plena integração na comunhão nacional. (BRASIL, 1973, n.p.).

Desconhecem-se, contudo, casos concretos de cidadãos ou comunidades que tenham requerido a emancipação. Fato interessante é que o Estatuto definia em seu Art. 16, § 3ำ, que "O órgão de assistência ao indígena propiciará o acesso, aos seus quadros, de índios integrados, estimulando a sua especialização indigenista" (BRASIL, 1973, n.p.). Isso criou uma expectativa em muitos indígenas de obterem empregos dentro ou perto de suas aldeias, a fim de reverter a escassez de oportunidades de obtenção de renda nesses lugares, ampliando o seu poder aquisitivo e melhorando o seu status social.

Centenas de indígenas vieram a ser contratados nos termos da Consolidação das Leis Trabalhistas e posteriormente obtiveram estabilidade com a Lei 8.112, de 1990, que passou a regulamentar o regime estatutário dos servidores públicos da União.

A partir da nova Constituição, o provimento de cargos efetivos na administração pública passou a ocorrer unicamente através de concurso público. Porém é possível entender o disposto no parágrafo 3 do artigo 16 do Estatuto "como uma determinação para que a FUNAI admita predominantemente índios em seus quadros de livre nomeação" (LIMA, 2011, p. 74-5).

A nomeação de indígenas para cargos de confiança continua acontecendo e é objeto de acirrada disputa por diferentes facções indígenas.

\section{O PROJETO DE EMANCIPAÇÃO INDÍGENA}

O assunto da emancipação começou a ganhar repercussão no governo do general Ernesto Geisel, em janeiro de 1975, quando o ministro do Interior, Maurício Rangel Reis, concedeu uma entrevista coletiva na qual informava que a Lei 6.001 poderia sofrer modificações para permitir a emancipação coletiva de povos inteiros. Ele voltou ao tema em abril do mesmo ano, ao dizer publicamente que a 
emancipação era um assunto do interesse dos próprios índios mais aculturados, destacando a importância de a FUNAI desenvolver nas áreas indígenas projetos especiais, de modo a garantir a autossuficiência das comunidades (COMISSÃO PRÓ-ÍNDIO, 1979).

Havia um entendimento do governo de que a prioridade não deveria ser assegurar aos índios a recuperação da posse de seus territórios, mas desenvolver nas áreas em que ocupavam projetos econômicos nos moldes que se aplicavam às populações camponesas.

Em outubro de 1976, o ministro tornou pública a existência de um anteprojeto que pretendia normatizar a emancipação, prevendo a possibilidade de extinguir a tutela por meio de decisão judicial a partir da requisição do órgão indigenista. Ainda, admitiu a intenção de agilizar os processos de emancipação de índios da região Sul e daqueles que viviam no atual Mato Grosso do Sul (COMISSÃO PRÓÍNDIO, 1979).

Uma revista publicada pela própria FUNAI no final daquele mesmo ano noticiava o seguinte plano do seu dirigente, o general Ismarth de Araújo Oliveira:

Após visitar as aldeias de Taunay e Ipegue, em Aquidauana, o presidente da FUNAI chegou à conclusão de que os índios Terena, daquela área, estão em avançado grau de aculturação e que para alcançarem a emancipação necessitam da implantação de projeto de desenvolvimento comunitário. Esse projeto será implantado pela FUNAl em janeiro próximo. (FUNAI, 1976, p. 64).

Ao proporem a emancipação, agentes do governo chegaram a pensar que o apelo à liberação de uma relação paternalista que significava a tutela fosse despertar uma reação favorável dos indígenas e de seus defensores, mas o que aconteceu foi o contrário (RAMOS, 2004). No final de 1976, ao anunciar as metas da política indigenista, Rangel Reis teria declarado:

Vamos procurar cumprir as metas fixadas pelo presidente Geisel, para que através de um trabalho concentrado entre vários Ministérios, daqui a 10 anos possamos reduzir para 20 mil os 220 mil índios existentes no Brasil e daqui a 30 anos, todos eles estarem devidamente integrados na sociedade nacional. (REIS apud COMISSÃO PRÓ-ÍNDIO, 1979, p. 11).

No dia 23 de janeiro de 1977, o ministro anunciava que a etnia Terena tinha o desejo de obter a emancipação (COMISSÃO PRÓ-ÍNDIO, 1979). Entretanto, as 
comunidades não haviam sido sequer consultadas. Uma matéria publicada em um jornal proclamava que, segundo anteprojeto do governo,

O primeiro caso de emancipação em perspectiva, no entanto, será de uma comunidade inteira, a dos índios Terena que vivem no pantanal do Mato Grosso. Totalizando 1.488 indivíduos, eles já alcançaram alto grau de aculturação, que permitirá, segundo a Funai, o cancelamento do regime tutelar. (LUCENA, 1977, n.p.).

Uma notícia que deu na imprensa em março de 1977, tratando dos preparativos para a recepção do presidente da República na aldeia de Taunay, confirmava que os Terena eram os indígenas apontados para receberem primeiramente a emancipação e que representantes dessa etnia estiveram em Brasília pouco tempo antes, contestando a medida, por não se considerarem ainda preparados (MINISTRO..., 1977). Havia bastante desinformação, e a maioria dos indígenas não tinha muita clareza do que pretendia essa proposta de emancipação e de quais seriam as suas consequências práticas, o que provocava apreensão e receio entre as lideranças.

A visita do Chefe de Estado aconteceu no dia 28 de abril de 1977. As aldeias Bananal e Ipegue receberam investimentos em infraestrutura para preparar a recepção. Foi instalada energia elétrica e reformadas as duas sedes dos postos da FUNAI, bem como três escolas, uma enfermaria e uma casa de hóspedes. Também foram construídos poços artesianos, chafarizes, um depósito para estocar a produção agrícola e um campo de pouso para aeronaves. Os índios, contudo, não se convenceram de que a emancipação seria proveitosa (DO CARMO, 1977) e redigiram um documento opinando que ainda não era o momento de se decidir sobre a retirada da condição tutelar. Os investimentos recebidos faziam parte de um planejamento para favorecer a integração da economia doméstica aos mercados regionais a partir do estímulo à produção.

Também em 1977, a Câmara dos Deputados instaurou uma Comissão Parlamentar de Inquérito (CPI) para investigar denúncias sobre invasão de terras indígenas, que realizou interrogatórios com indígenas e agentes do campo indigenista, buscando informações e opiniões inclusive sobre a questão da emancipação. Dentre os interrogados estava o terena Jair de Oliveira, presidente da Câmara Municipal de Aquidauana. 
Em reportagem de março de 1977, Jair é mencionado na fala de Rangel Reis como um caso emblemático de índio com capacidade civil plena, exemplo de que toda a população Terena estaria em condições de ser emancipada (EMANCIPAÇÃO..., 1977). Outra matéria publicada um ano depois informava que o Ministério do Interior havia concluído a minuta de decreto que, no entendimento desta pasta, corrigiria injustiças toleradas pela Lei 6.001, havendo de considerar que

Há inúmeros casos de índios já perfeitamente integrados à civilização, como, por exemplo, o do presidente da Câmara de Vereadores de Aquidauana, Jair de Oliveira, da tribo terena, os quais, no entanto, continuam gozando de todos os benefícios da tutelagem governamental: não pagam impostos, não respondem criminalmente perante a lei, além de ter sempre direito à posse da terra da tribo de origem. Isso tudo sem contar os favores hoje oferecidos aos menores de idade (O QUE..., 1978, p. 3).

Esse julgamento tendencioso inferia que o indígena não se emancipava somente para continuar obtendo "favores" (e não direitos) concedidos por um Estado paternalista.

Em depoimento à CPI, Jair admitiu que o seu povo ansiava pelo "progresso econômico, cultural e espiritual", porém, quando se percebeu que a emancipação poderia acarretar a retirada da assistência da FUNAI nas aldeias, os líderes decidiram não aceitar a proposta nos termos que estavam colocados. O vereador exaltou que se sentia bem integrado à sociedade brasileira e que o status que conquistou deveu-se apenas ao seu próprio esforço, nunca dependendo da assistência da FUNAI. Por isso mesmo, jamais cogitou pedir para si a emancipação. Jair também declarou que compreendia a recusa de seus patrícios, pois grande parte deles não estava no mesmo grau de integração que ele próprio e prescindia da intensificação da ajuda do órgão, pincipalmente na área agrícola (OLIVEIRA, 1978).

Em 2 de fevereiro de 1978, Rangel Reis divulgou que Geisel assinaria naquele mês um decreto para liberar indígenas da tutela. Um importante periódico descrevia que

A medida abrangerá cerca de 2 mil índios e o Ministro do Interior pretende emancipar cerca de 100 no atual Governo, entre os quais apontou o cacique Mário Juruna, o Vereador Jair, de Aquidauana e a comunidade dos Terenas, "para servir de exemplo aos demais". A Funai não terá obrigações para com 
o índio ou a comunidade indígena que pedirem emancipação, mas thes dará títulos de posse e domínio da terra, como compensação. O prazo de carência para qualquer negociação com estas terras será de 10 anos e esse tipo de proteção não beneficiará o índio que morar em cidades (GEISEL..., 1978 , n.p.).

Em uma publicação do Ministério do Interior de agosto de 1978, o titular da pasta reitera o compromisso com a formulação de um decreto para regulamentar a emancipação e anuncia que:

O objetivo básico a médio e longo prazo é a verdadeira integração do índio à comunhão nacional, é proporcionar-Ihe plena consciência de que é um brasileiro-índio, fazendo parte de uma sociedade que abriga diferentes raças e credos, sem qualquer tipo de discriminação racial. Tem-se firme convicção de que esse objetivo pode e deve ser alcançado no futuro; de que índio não é um ser diferente, para viver segregado em reservas, mas que deve participar do esforço do desenvolvimento nacional (REIS, 1978, p. 83).

Uma matéria publicada no jornal sul-mato-grossense $O$ Progresso trazia a fala do general Ismarth justificando que o anúncio do decreto de emancipação não deveria causar surpresa, porque a própria Convenção no 157 da Organização Internacional do Trabalho (OIT), da qual o Brasil era signatário, estabelece a emancipação dos indígenas. Na mesma página, aparece estampada uma foto do terena Ramão Machado, citado na legenda como "um exemplo de emancipação" (RANGEL..., 1978, p. 1).

A mencionada Convenção, que é de 1957, de fato, em seu artigo 2o, item 1, estipula que "Competirá principalmente aos governos pôr em prática programas coordenados e sistemáticos com vistas à proteção das populações interessadas e sua integração progressiva na vida dos respectivos países". Entretanto, no item 4 do mesmo artigo, determina que "Será excluída a força ou a coerção com o objetivo de integrar as populações interessadas na comunidade nacional"3 (OIT, 1957, n.p.). A maneira como o governo vinha agindo, entretanto, deixa clara a existência de coerção.

A FUNAI promoveu em setembro de 1978, em Brasília, um evento intitulado "Encontro de Antropólogos e Indigenistas, sobre a regulamentação de dispositivos do Estatuto do Índio", no qual Ismarth colocou em discussão a minuta do decreto

\footnotetext{
${ }^{3}$ A Convenção 169 da OIT, de 1989, revogou o viés integracionista da Convenção 157.
} 
que tratava da emancipação, ouvindo dos participantes a opinião unânime de que naquele instante a prioridade do governo deveria ser a demarcação das terras indígenas, cujo prazo de cinco anos estabelecido pela Lei 6.001 estava quase expirando. A retirada do regime tutelar foi considerada inoportuna, "tendo em vista o fato de ainda não haver uma relação de equidade entre as sociedades indígenas e a sociedade nacional" (BIGIO, 2007b, p. 124). A posição dos antropólogos e indigenistas, segundo a imprensa, "foi recebida com irritação pelos assessores do ministro Rangel Reis, que a interpretaram como uma barreira a qualquer diálogo sobre a emancipação" (ANTROPÓLOGOS..., 1978, p. 14).

À medida que os indígenas foram se informando da questão, perceberam que

[...] emancipar-se representava deixar de ser índio. Porque transformados em meros brasileiros, eles passariam a viver em terras que seriam objeto de propriedade privada e, portanto, alienáveis, pois no entender dos legisladores, os índios só teriam direito ao uso exclusivo e permanente de suas terras na condição de se manterem como menores tutelados pelo estado. (RAMOS, 2004, p. 177).

Em 3 de novembro de 1978, o Ministério do Interior comunicou que a Presidência da República tomara a decisão de suspender temporariamente a proposta de emancipação (COMISSÃO PRÓ-ÍNDIO, 1979). Em 8 de novembro, foi organizado na Pontifícia Universidade Católica de São Paulo um ato de protesto que reuniu mais de 2.000 pessoas. Naquela oportunidade, mais de 100 entidades manifestaram desacordo com o projeto. Um dos participantes de destaque no protesto foi o estudante de Direito e funcionário público terena Maurício Pedro, que residia na cidade de Campinas e declarava que a emancipação compulsória seria prejudicial aos índios, pois nem mesmo ele, que morava havia muitos anos longe de sua aldeia, sentia-se apto para competir em pé de igualdade na sociedade dos brancos (ATO..., 1978).

Em livro publicado dois anos antes, Cardoso de Oliveira (1976, p. 134) chegou à conclusão de que

[...] a população Terêna, ainda que integrada à estrutura econômica regional, nem por isso será - num futuro previsível - assimilada pela sociedade brasileira ou por seus segmentos sócio-culturais. Talvez nem mesmo isso chegue a ocorrer algum dia, se persistirem as mesmas condições que têm 
levado a quase totalidade dessa população a permanecer aldeada. A assimilação de alguns indivíduos, geralmente filhos e netos de índios emigrados de suas comunidades, não é suficiente para nos permitir diagnosticar a população Terêna, em seu conjunto, como em vias de incorporação à sociedade nacional.

Passados mais de 40 anos dessa afirmação, essa incorporação não parece estar nem perto de se confirmar, mesmo tendo a migração para as cidades e os casamentos com não indígenas se intensificado sobremaneira. Na opinião do citado antropólogo,

[...] a chamada capacidade empresarial dos Terêna (considerada como um dos indicadores mais expressivos de sua emancipação) está presente num número reduzidíssimo de indivíduos. Se é verdade que há pequenos empresários indígenas, com suficiente iniciativa para se utilizar - ainda que com variável eficiência - das regras do jogo econômico imperante na sociedade regional alienígena, há uma imensa maioria cuja única chance - se emancipada - será atrelar-se às camadas menos favorecidas da sociedade nacional. Uma emancipação nessas circunstâncias representaria a institucionalização de uma estratificação social altamente lesiva aos interesses indígenas, uma vez que seria uma cunha a mais a dividir, e por suposto, desorganizar a vida tribal. (CARDOSO DE OLIVEIRA, 1979, p. 57-8).

A tentativa de legislar sobre a emancipação removeu os indígenas da invisibilidade, já que a imprensa pouco falava deles até então. Ramos (1995) classificou essa fase como "o momento heroico do indigenismo", enaltecendo que

[...] antropólogos, advogados, jornalistas, religiosos e artistas se revezaram num inflamado palco político com líderes indígenas que, como por encanto, afloraram na cena pública, tomando de assalto os meios de comunicação [...]. Embalados pelo sucesso de seus protestos, que conseguiram engavetar o projeto de emancipação, os índios criaram a União das Nações Indígenas e os brancos se organizaram em uma proliferação de entidades de apoio ao índio. (RAMOS, 1995, p. 6).

Ao participarem de assembleias promovidas pelo Conselho Indigenista Missionário (CIMI) nos anos 1970, lideranças indígenas nacionais se deram conta de problemas comuns enfrentados em suas comunidades e, a partir disso, construíram uma identidade pan-indígena instrumentalizada na arena política (PACHECO DE OLIVEIRA; FREIRE, 2006). Mas o assunto da emancipação, que parecia então enterrado, foi resgatado pelo governo poucos anos mais tarde. 


\section{A PRESSÃO SOBRE OS ÍNDIOS SERVIDORES DA FUNAI}

O tema voltou à pauta em 1981, quando o coronel João Carlos Nobre da Veiga assumiu a presidência da FUNAI, admitindo que a fundação estava estudando propor alterações no Estatuto do Índio que permitissem conceder emancipação ex-ofício de indivíduos indígenas (FUNAI..., 1981d). Em janeiro daquele ano, o coronel havia declarado à imprensa que entendia que o Estatuto preconizava que somente índios integrados teriam direito de ingressar nos quadros da autarquia (íNDIOS..., 1981a).

No órgão, o ambiente era tenso porque, no ano anterior, funcionários haviam sido demitidos sob alegação de insubordinação. Dentre os alvos da medida emancipatória poderiam estar os índios funcionários, já que fora noticiado em fevereiro daquele ano o seguinte:

Os 250 índios que trabalham para a Funai poderão vir a ser submetidos a uma legislação especial, que definirá se eles conservarão a tutela do órgão ou adquirirão responsabilidade civil perante o Estado. Desses índios, dois trabalham na sede da Funai em Brasília e os outros estão espalhados pelo país, em delegacias regionais e postos indígenas. Atualmente são regidos pela CLT e pagam encargos sociais, recebendo entre um e quatro salários mínimos e trabalhando como auxiliares de ensino, atendentes em ambulatórios, motoristas. A emancipação desses índios é vista como desejável pela Funai, diante de casos como o de Marcos Terena que, embora seja piloto, não pode prestar concurso para a Funai, porque a companhia de seguros recusa contrato de tutelados. (FUNAI..., 1981b, p. 17).

Marcos Terena, cujo nome de batismo era Mariano Justino Marcos, tinha na época 28 anos, cursava faculdade de Administração de Empresas, havia concluído o curso de especialização em voo por instrumentos na Academia da Força Aérea, possuía brevê de piloto comercial e já havia pilotado aeronaves da FUNAI mesmo sem vínculo empregatício com a instituição (DEPUTADO..., 1981).

Este caso ganhou repercussão nacional e se tornou emblemático da luta indígena. Foi generalizada a interpretação de que estava sendo imposta a ele uma exigência de negar a identidade étnica em troca do emprego. A recusa de Marcos soava como um gesto representativo da vontade coletiva indígena de resistir ao colonialismo interno. Na época, o jovem (TERENA, 1981) chegou a declarar que, se aceitasse o cargo em troca do pedido de emancipação, estaria traindo não 
apenas a sua própria condição de índio, mas todo o seu povo e as outras nações indígenas brasileiras.

Relembrando dessa situação anos mais tarde, Marcos desabafou:

Entre voltar a ser branco e continuar piloto, e a voltar a ser índio, mesmo sendo subversivo, optei pela volta às minhas origens e me senti um verdadeiro filho pródigo. Sabia ler, escrever, falar o português, o espanhol e interpretar o inglês, o francês. Sabia analisar a situação política, econômica e social do nosso país. Por isso não pude ser enquadrado como um índio padronizado na cabeça dos dirigentes do órgão tutor, e como castigo vi por três anos ser impossível pilotar mesmo nas aeronaves do órgão, pois, segundo eles, era impossível admitir um índio pilotando. Afinal, o índio era incapaz perante a lei. (TERENA, 1990, p. 6).

Em fevereiro de 1981, a FUNAI, por meio de sua assessoria de comunicação, deu uma resposta contundente às críticas que vinha recebendo de Marcos, alegando que este universitário deveria ter um mínimo de reconhecimento pelo fato de estar sendo beneficiado pela fundação desde 1977 através do custeio de uma bolsa de estudos, alimentação e abrigo em Brasília, além de o órgão prover a obtenção de sua carteira profissional como piloto e permitir que o jovem usasse aeronaves oficiais para completar suas horas de voo necessárias para tirar o brevê, recebendo também diárias, refeições e o direito de fazer telefonemas. A instituição notificava ainda que o terena não fora contratado por não atender a requisitos técnicos previstos em edital (FUNAI..., 1981c). A nota também mencionava a questão de a seguradora se recusar a firmar contrato com um piloto tutelado. O que chamou a atenção foi a passividade da FUNAI em aceitar esse suposto ato discriminatório. Causava perplexidade também a acusação de que Marcos estaria sendo ingrato, como se o órgão estivesse lhe prestando um favor ao conceder-Ihe assistência estudantil, quando, na verdade, seria uma obrigação.

Em agosto de 1981, Nobre da Veiga declarou a um jornal que se a FUNAI ainda conferia assistência a um indígena que havia deixado sua comunidade para morar na cidade é porque mantinha uma atitude de respeito e consideração para com aquele sujeito, embora a entidade não tivesse o dever de continuar o apoiando. Ainda afirmava que diversos indivíduos assumiam a identidade indígena apenas quando Ihes convinha, mencionando como exemplo o próprio Marcos, 
que havia viajado no mês anterior para o Equador sem ter solicitado a anuência do órgão tutor (FUNAI..., 1981f).

Tal avaliação é paradoxal, pois, se de um lado julga correto a FUNAI desincumbir-se da responsabilidade de assistir ao índio vivendo em contexto urbano, de outro, considera imprescindível a autorização da entidade para viajar para o exterior.

\section{A CRIAÇÃO DA UNIND E O BOICOTE DO GOVERNO A ESTA ENTIDADE}

Marcos liderava um grupo complementado por estudantes secundaristas de etnias diversas que, no começo dos anos 1980, estava morando na capital federal e recebendo auxílio da FUNAI na forma de bolsas de estudo e alojamento, até que a direção do órgão decidiu enviá-los de volta para suas regiões de origem, oferecendo-lhes em troca empregos públicos. Aqueles que resistiram vivendo em Brasília fundaram uma entidade chamada União das Nações Indígenas (UNIND) (BICALHO, 2010).

Em abril de 1980, a UNIND foi oficializada, incluindo estudantes pertencentes aos povos Bakairi, Bororo, Canela, Karajá, Pataxó, Terena, Urubu-Kaapor e Xavante. Em agosto daquele ano, outra organização, com o mesmo propósito de representar nacionalmente o movimento indígena, batizada com o mesmo nome, mas com a sigla UNI, foi formalizada, tendo à frente Domingos Veríssimo Marcos (tio de Marcos Terena). As duas agremiações foram unificadas sob a sigla UNI e, em abril de 1981, o sobrinho foi eleito seu presidente em uma assembleia (SANT'ANA, 2010).

Acerca da organização do movimento indígena na década de 1980, Pacheco de Oliveira e Freire (2006, p. 194) contam que "à medida que crescia o movimento surgiam também divergências e iniciativas autônomas entre os índios". Segundo Ferreira (2017), dentro da própria UNI, em 1982, ocorreu um desentendimento entre Domingos e seu sobrinho, quando ambos passaram a se considerar presidentes da organização, impasse que terminou com a saída de Marcos do comando.

Em março de 1981, havia sido anunciado na imprensa que o presidente da República, general Figueiredo, era contrário à UNIND e proibira que a FUNAI desse qualquer suporte àquela entidade, por considerá-la apadrinhada por gente que pretendia tornar a relação dos índios com a política indigenista oficial 
incompatível (FIGUEIREDO..., 1981). Pouco depois, Nobre da Veiga declarou que a organização indígena seria ilegal porque os indivíduos que a compunham não tinham a plena capacidade civil e assim seriam equiparados aos menores de idade (FUNAI..., 1981e).

A atuação da UNI incomodou tanto a direção da FUNAI, que esta, em retaliação, decidiu interromper o convênio com a Casa do Ceará, onde os estudantes ficavam alojados (JURUNA; HOHLFELDT; HOFFMAN, 1982). Para não serem mandados de volta para Campo Grande, quatro índios Terena (Samuel, Newton, Sebastião e Vilson) tiveram de recorrer à Justiça (TRF..., 1981). Marcos, que a essa altura trabalhava em uma assessoria na Câmara dos Deputados, foi surpreendido pela notícia de que sua matrícula havia sido transferida para uma faculdade na capital sul-mato-grossense (SEM..., 1981).

A respeito da transferência compulsória dos estudantes, a imprensa reverberou:

A Fundação Nacional do Índio, com o objetivo de desarticular a União Nacional das Nações Indígenas, criada por 15 índios estudantes em Brasília, suspendeu o convênio com uma instituição filantrópica, onde eles moram e deu um prazo de três dias para que se mudem.

O diretor do Departamento Geral de Projetos Comunitários, Coronel Ivan Zanoni Hausen afirmou que a medida obedece à legislação, pela qual os índios devem permanecer o mais próximo possível de suas aldeias. (ÍNDIOS..., 1981b, p. 8).

Na época, Marcos teria declarado a jornalistas que representantes da agência indigenista tentaram fomentar uma cisão no grupo de estudantes apelando para pressões psicológicas e oferta de bolsas de estudos em outros estados, conseguindo convencer alguns indivíduos (FUNAI..., 1981a). Comentando este episódio muito tempo depois, o indígena afirmara que "o General Golbery do Couto e Silva determinou que o Presidente da Funai, Coronel do Exército João Carlos Nobre da Veiga, expulsasse aqueles indígenas, quando 'chegaram à conclusão' de que o índio jamais deveria acessar o 1 으 e 2 o graus e, muito menos, a universidade" (TERENA, 2003, p. 100).

O livro O gravador do Juruna traz a transcrição de uma reunião ocorrida na sede da FUNAI ainda em 1981, em que Marcos Terena e seu irmão mais novo, Carlos - que era estudante secundarista -, acompanhados por outros estudan- 
tes indígenas, discutem acaloradamente com um coronel diretor do órgão por causa da decisão que afetou os índios que viviam na capital nacional (JURUNA; HOHLFELDT; HOFFMAN, 1982). Suspeitava-se de que a FUNAI pretendia na verdade afastar o jovem líder dos principais canais de comunicação do país e dificultar a sua participação em fóruns onde sua voz vinha tendo alcance.

Analisando os fatos, faz sentido a afirmação de Cardoso de Oliveira (1988) de que naquele momento a FUNAI mostrava indiferença ao movimento indígena e somente dialogava com aqueles índios que não contestavam as premissas da política do Estado, "tendo procurado praticar uma política menor de cooptação através de distribuição de empregos, tornando esses índios-funcionários em simples repetidores do discurso oficial" (CARDOSO DE OLIVEIRA, 1988, p. 71).

Na FUNAI, a maioria dos indígenas contratados nos anos 1970 e 1980 ocuparam posições subalternas e de baixa qualificação, de onde pouco ou nada podiam influenciar nas decisões importantes do indigenismo.

Em julho de 1982, Marcos finalmente ingressou no quadro funcional como piloto 4 . Nesse momento, a autarquia era presidida pelo coronel Paulo Moreira Leal. Em maio de 1984, o advogado Jurandy Marcos da Fonseca foi apresentado como o novo presidente do órgão e anunciou a escolha de Marcos Terena para o cargo de chefe de gabinete e Megaron Txucarramãe para a chefia do Parque Indígena do Xingu. Uma repórter descreveu que pelos corredores da fundação a notícia causou grande furor e servidores que até então ironizavam os indígenas ficaram perplexos (MOREIRA, 1984).

$\mathrm{Na}$ investidura do cargo, o novo chefe de gabinete sofreu ataques verbais por não abrir mão do direito à tutela. Em sessão da Câmara dos Deputados em maio de 1984, o parlamentar João Batista Fagundes fez um pronunciamento contundente em que anunciou a aprovação na Comissão de Constituição e Justiça daquela casa de um projeto de sua autoria visando à emancipação dos indígenas e, por fim, questionou de modo agressivo a postura de Marcos, dizendo que

É muito interessante conservar eternamente a condição de índio para fins de Imposto de Renda, desde que possa exercer a função de branco para fins de contra-cheque em uma função D.A.S.

${ }^{4}$ Informação extraída da página eletrônica Portal da Transparência, mantida pelo governo federal. Disponível em: www.portaldatransparencia.gov.br. Acesso em: 14 fev. 2018. 
Não sei como o novo Presidente da FUNAl irá justificar a investidura de um elemento juridicamente incapaz para uma função que exige o pressuposto legal da capacidade civil. E, se houver a plena capacidade de entender as filigranas da burocracia administrativa que existe em Brasília e não existe na selva, há todas as condições para a Emancipação pretendida por meu projeto, que a prevê para os índios portadores de curso superior que já atingiram a plena maturidade para entender as peculiaridades da sociedade dita civilizada. (FAGUNDES, 1984, p. 3.189).

De modo provocativo, o deputado prosseguia:

[...] quando tiver capacidade para exercer cargos de direção e assessoramento na Capital da República, disputando em igualdades de condições um mercado de trabalho com branco de nível superior, ele não é mais índio. É um brasileiro igual aos demais. (FAGUNDES, 1984, p. 3.189).

Na perspectiva antropológica, tal declaração se mostra absolutamente equivocada.

Marcos ainda teve de dar explicações a seus próprios aliados, pois, de acordo com Ramos (1990, p. 133), sua nomeação para um cargo de destaque em plena ditadura foi percebida como algo ambíguo pelo ativismo indígena. Ele sofreu acusações de companheiros de movimento e de outros apoiadores de ter sido cooptado pela máquina do Estado, mesmo tendo prosseguido com críticas à política indigenista oficial.

Um dos críticos indiretos de Marcos foi o sertanista Apoena Meireles, que disse a jornalistas que Jurandy, fazendo concessões, havia conseguido silenciar indígenas e ex-funcionários que costumavam contestar a presidência do órgão. Terena rebateu afirmando que Apoena fazia parte de uma ala mais conservadora incomodada com a ascensão de índios a funções de comando no órgão (CACIQUES..., 1984).

As nomeações de índios, segundo Ramos (1990), seria uma estratégia da FUNAI para dividir o movimento indígena e assim facilitar a sua dominação, fazendo emergir a figura do "índio-funcionário", que abarcava "uma categoria de jovens, aparentemente oportunistas, mais interessados no emprego do que na causa indígena, que preferiram se opor ao movimento a pôr em risco seus cargos recém adquiridos" (RAMOS, 1990, p. 134), da qual a autora faz questão de frisar que Marcos Terena e outros tantos não se incluíam. 
Pacheco de Oliveira (2006, p. 138) menciona que os servidores indígenas da FUNAI na década de 2000 eram predominantemente das etnias Fulniô, Pankararu, Kaingang, Terena, Karajá e Xavante e estavam operando em funções menos especializadas, "como barqueiro, motorista, guia, assistente de indigenista, chefe substituto do Posto, monitor bilíngue, ou agente de saúde". O autor avalia que as trajetórias profissionais deles "são nitidamente marcadas pela crescente individualização do sujeito frente à coletividade de origem e pela progressiva adaptação a papéis e modelos de personalidade exportados pelos brancos". ${ }^{5}$ Entretanto, poderíamos afirmar seguramente que, para os indígenas, a oportunidade de ocupar espaços na instituição não representava apenas uma estratégia de interesses individualistas.

Sant'Ana (2010, p. 176) tem razão ao destacar que

[...] dentro da estrutura do poder estatal, os Terena podiam não só ter acesso aos bens necessários para o aumento do prestígio e poder junto à sua parentela e demais de suas linhas de relações, mas, também, podiam direcionar ou pressionar por mudanças nas políticas indigenistas e municipais, indo muito além da concepção de "índio funcionário", cumpridor do seu dever, ou cuidador apenas da sua parentela.

Em março de 1985, Marcos deixou a chefia de gabinete para assumir a Assessoria de Assuntos Indígenas do Ministério da Cultura. Posteriormente, ocupou funções em diversos órgãos governamentais e organismos internacionais. Mas esse líder também viveu momentos difíceis ao retornar para a FUNAI. Em 1990, denunciou que vinha sofrendo perseguições, tendo sido colocado em disponibilidade. Dizia ainda que raramente era escalado para voos oficiais e que sempre era designado para missões arriscadas, em que havia conflito, já que outros pilotos tinham receio de encarar a situação. $O$ aviador acreditava que o seu isolamento era promovido pelos dirigentes do órgão em retaliação às críticas públicas que fazia (TERENA, 1990).

Mesmo após a redemocratização do país, planos de emancipação foram cogitados durante o governo do presidente José Sarney (BIGIO, 2007a). A UNI, junto de outras entidades, teve uma atuação importante na Assembleia Nacional Constituinte em 1987, que resultou na inclusão de uma proposta de artigos sobre direitos indígenas na nova Constituição. Nenhum dos oito indígenas que se candidataram ao

5 Tradução livre a partir do idioma Espanhol. 
cargo de deputado no ano anterior - incluindo Marcos Terena - se elegeu, mas o lobby das lideranças fez com que os parlamentares refutassem uma proposta em trâmite que visava estabelecer um tratamento jurídico diferenciado entre índios "aculturados" e "não aculturados" (PACHECO DE OLIVEIRA; FREIRE, 2006).

\section{A NOVA CONSTITUIÇÃO E A SUPERAÇÃO DA TUTELA RESTRITIVA}

A Constituição promulgada em 1988 contém o capítulo VIII tratando exclusivamente de direitos indígenas. O caput do Art. 231 estabelece que "São reconhecidos aos índios sua organização social, costumes, línguas, crenças e tradições, e os direitos originários sobre as terras que tradicionalmente ocupam, competindo à União demarcá-las, proteger e fazer respeitar todos os seus bens" (BRASIL, 1988, n.p.).

Na visão de especialistas, a nova Carta Magna rompe com a orientação integracionista e com a interpretação paternalista da tutela, "inaugurando uma nova ordem jurídica que reconhece o direito à diferença e a capacidade civil do índio, sua comunidade e sua organização própria" (AMADO, 2016, p. 263), permitindo aos povos originários e seus integrantes "associarem-se livremente de maneira a representar seus interesses sem a interveniência da agência indigenista" (PACHECO DE OLIVEIRA, 2016, p. 204), propiciando inclusive a "possibilidade de contrair direitos e assumir obrigações na ordem jurídica” (LIMA, 2011, p. 52).

Em suma, a tutela continuou existindo, mas com uma conotação diferente da de então. Como frisaram Castilho e Fernandes (2003, p. 17),

A tutela dos índios, como instituto de direito público, deve significar assistência efetiva em questões de direitos fundamentais e proteção de territórios indígenas, no plano físico e cultural, sem paternalismo ou corporativismo. Ademais, a configuração legal e a aplicação na prática deve ser orientada pela participação ativa dos índios, buscando fortalecer a sua autonomia.

Os povos indígenas, portanto, gozam atualmente de todos os direitos estendidos a qualquer cidadão nacional "além da legislação específica, que visa resguardar e proteger seus direitos culturais especiais, bem como o direito de permanecerem como sociedades diferenciadas dentro do Estado brasileiro" (GUARANY, 2006, p. 163).

Está claro então que nada impede, por exemplo, que um servidor público indígena responda administrativa e judicialmente por seus atos. 


\section{CONSIDERAÇÕES FINAIS}

São inegáveis as mudanças culturais sofridas historicamente pelos Terena e acentuadas nas últimas décadas com o grande afluxo populacional das aldeias para as cidades. Todavia, esse não é um fator que faz com que eles permaneçam menos ou mais índios. Não se abandona a identidade e não se perdem a cultura diferenciada e a lealdade grupal por causa da profunda convivência interétnica.

Nesse longo tempo de interação com os não índios, apesar de terem sido submetidos a uma série de violências e privações, os Terena, para não desaparecerem, aprenderam a negociar na vivência da alteridade elementos que pautam sua experiência de pertencimento à nação brasileira. Mas, no limite dessa margem de negociação, foi se firmando um modo de ser peculiar que resiste à sua absorção completa e, "acima de tudo, recusa a anulação de sua própria identidade" (ROCHA, 2003, p. 127).

Faz sentido então a afirmação de Pereira (2009, p. 128) de que os membros dessa etnia pretendem manter a sua tradição, "mas não a desejam de modo fundamentalista, pois encontram na relação com outros grupos étnicos espaços para a atualização de seu modo próprio de ser".

Concluímos, assim, que as tentativas de emancipação propostas se caracterizaram pela violência institucional de um Estado autoritário e colonialista. Os indígenas, porém, mostraram-se capazes de resistir bravamente e manter sua autonomia até os dias de hoje.

\section{REFERÊNCIAS}

AMADO, Luiz Henrique Eloy. Direito dos povos indígenas e legislação indigenista. In: URQUIZA, Antônio Hilário Aguilera (Org.). Antropologia e história dos povos indígenas de Mato Grosso do Sul. Campo Grande: Ed. UFMS, 2016. p. 251-99.

ANTROPÓLOGOS criticam emancipação. O Estado de São Paulo, São Paulo, 13 set. 1978. p. 14.

ATO público repudia emancipação indígena. Folha de São Paulo, São Paulo, 9 nov. 1978. Nacional, p. 9.

AZANHA, Gilberto. As terras indígenas Terena no Mato Grosso do Sul. Revista de Estudos e Pesquisas, FUNAl, Brasília, v. 2, n. 1, p. 61-111, jul. 2005. 
BICALHO, Poliene Soares dos Santos. Protagonismo indígena no Brasil: movimento, cidadania e direitos (1970-2009). 2010. Tese (Doutorado em História) - Instituto de Ciências Humanas, Universidade de Brasília, Brasília, 2010.

BIGIO, Elias dos Santos. A ação indigenista brasileira sob a influência militar e da Nova República (1967-1990). Revista de Estudos e Pesquisas, Brasília, v. 4, n. 2, p. 13-93, dez. 2007a.

BIGIO, Elias dos Santos. Programa(s) de índio(s): falas, contradições, ações institucionais e representações sobre os índios no Brasil e na Venezuela (1960-1992). 2007. Tese (Doutorado em História) - Instituto de Ciências Humanas, Universidade de Brasília, Brasília, 2007b.

BRASIL. Constituição da República Federativa do Brasil. Brasília, 5 de outubro de 1988. Disponível em: http://www.planalto.gov.br/ccivil_03/Constituicao/Constituicao.htm. Acesso em: 10 set. 2018.

BRASIL. Lei n. 6.001, de 19 de dezembro de 1973. Dispõe sobre o Estatuto do Índio. Brasília: Congresso Nacional, 1973. Disponível em: http://www.planalto.gov.br/ccivil_03/ Leis/L6001.htm. Acesso em: 10 set. 2018.

CACIQUES rejeitam portaria da Funai e dão prazo a Andreazza. Jornal do Brasil, Rio de Janeiro, 16 jul. 1984. 1o Caderno, p. 4.

CARDOSO DE OLIVEIRA, Roberto. A crise do indigenismo. Campinas, SP: Ed. Unicamp, 1988.

CARDOSO DE OLIVEIRA, Roberto. Terena. Cadernos da Comissão Pró-índio/SP, São Paulo, n. 1, p. 55-8, ago. 1979.

CARDOSO DE OLIVEIRA, Roberto. Do índio ao bugre: o processo de assimilação dos Terena. Rio de Janeiro: Livraria Francisco Alves, 1976.

CARDOSO DE OLIVEIRA, Roberto. Urbanização e tribalismo: a integração dos índios Terêna numa sociedade de classes. Rio de Janeiro: Zahar, 1968.

CARVALHO, Edgar de Assis. A alternativa dos vencidos: índios Terena no Estado de São Paulo. Rio de Janeiro: Paz e Terra, 1979.

CARVALHO, Silvia M. Schmuziger. Chaco: encruzilhada de povos e "melting pot" cultural. In: CARNEIRO DA CUNHA, Manuela (Org.). História dos índios no Brasil. São Paulo: Companhia das Letras, 1992. p. 457-74. 
CASTILHO, Ela Wiecko Volkmer de; FERNANDES, Rafael Estêvão. A problemática da tutela dos povos indígenas do Brasil. In: BRASIL. Ministério das Relações Exteriores. A questão indígena. Brasília: MRE, 2003. p. 15-8.

COMISSÃO PRÓ-ÍNDIO. Histórico da emancipação. Cadernos da Comissão Pró-índio/SP, São Paulo, n. 1, p. 9-16, ago. 1979.

CUNHA, Manuela Carneiro da; ALMEIDA, Mauro Wagner Berno de. Populações tradicionais e conservação ambiental. In: CUNHA, Manuela Carneiro da. Cultura com aspas e outros ensaios. São Paulo: Cosac Naify, 2009. p. 277-300.

DEPUTADO quer mandado para Marcos Terena. Correio Braziliense, Brasília, 9 jan. 1981. Disponível em: https://pib.socioambiental.org/es/Not\%C3\%ADcias?id=164427. Acesso em: 18 nov. 2019.

DINIZ, Edson Soares. Os Guarani e os Terena da Reserva Indígena de Araribá. Revista do Instituto de Estudos Brasileiros, São Paulo, n. 21, p. 7-16, 1979.

DO CARMO, Vitu. O quadro indígena, retocado para Geisel ver. O Estado de São Paulo, São Paulo, 28 abr. 1977. Geral, p. 84.

EMANCIPAÇÃO cria "oportunidades" ao índio, diz ministro. O Estado de São Paulo, São Paulo, 23 mar. 1977. p. 19.

EREMITES DE OLIVEIRA, Jorge; PEREIRA, Levi Marques. "Duas no pé e uma na bunda": da participação terena na guerra entre o Paraguai e a Tríplice Aliança à luta pela ampliação dos limites da Terra Indígena Buriti. História em Reflexão, Dourados, MS, v. 1, n. 2, p. 1-20, jul./dez. 2007.

FAGUNDES, João Batista. Pronunciamento na tribuna da Câmara dos Deputados. Diário do Congresso Nacional (Seção 1) - Brasília, 10 de maio de 1984. p. 3.189.

FERREIRA, Andrey Cordeiro. Etnopolítica e Estado: centralização e descentralização no movimento indígena brasileiro. Anuário Antropológico, Brasília, v. 42, n. 1, p. 195-226, 2017.

FERREIRA, Andrey Cordeiro. Tutela e resistência indígena: etnografia e história das relações de poder entre os Terena e o Estado brasileiro. São Paulo: EDUSP, 2007.

FIGUEIREDO contra a Unind e favorável à emancipação. Folha da Tarde, São Paulo, 30 mar. 1981. Disponível em: https://documentacao.socioambiental.org/noticias/anexo_ noticia/36857_20160713_103420.pdf. Acesso em: 14 set. 2018. 
FUNAI cala sobre saída de índios. Jornal do Brasil, Rio de Janeiro, 30 jan. 1981a. Nacional. p. 16.

FUNAl quer emancipar 250 índios. Jornal do Brasil, Rio de Janeiro, 4 fev. 1981b. Nacional, p. 17.

FUNAl explica caso do índio piloto. Folha da Tarde, São Paulo, 26 fev. 1981c. Disponível em: https://documentacao.socioambiental.org/noticias/anexo_ noticia/35607_20160510_123417.pdf. Acesso em: 14 set. 2018.

FUNAI admite estudo para mudar estatuto. O Estado de São Paulo, São Paulo, 11 mar. 1981d. Geral, p. 12.

FUNAl assina convênio de Cr\$15 milhões para os índios de Guarita no Sul. Jornal do Brasil, Rio de Janeiro 12 jun. 1981e. Nacional, p. 15.

FUNAI acha justo emancipar índios destribalizados. O Estado de São Paulo, São Paulo, 9 ago. 1981f. Geral, p. 29.

FUNDAÇÃO NACIONAL DO ÍNDIO (FUNAI). Notícias. Revista de Atualidade Indígena, Brasília, ano 1, n. 1, nov./dez. 1976.

GEISEL assinará este mês projeto de decreto sobre a emancipação dos índios. Jornal do Brasil, Rio de Janeiro, 4 fev. 1978.

GUARANY, Vilmar Martins Moura. Desafios e perspectivas para a construção e o exercício da cidadania indígena. In: ARAÚJO, Ana Valéria (Org.). Povos indígenas e a lei dos "brancos": o direito à diferença. Brasília: MEC, 2006. p. 146-66.

ÍNDIOS não vão ser emancipados, afirma a FUNAI. Correio Braziliense, Brasília, 13 jan. 1981a. Disponível em: https://documentacao.socioambiental.org/noticias/anexo_ noticia/36788_20160711_104530.pdf. Acesso em: 14 set. 2018.

ÍNDIOS fora de casa. Jornal do Brasil, Rio de Janeiro, 29 jan. 1981b. Nacional. p. 8.

JURUNA, Mário; HOHLFELDT, Antonio; HOFFMANN, Assis. O gravador do Juruna. Porto Alegre: Mercado Aberto, 1982.

LIMA, Edilson Vitorelli Diniz. Estatuto do Índio. Lei n. 6.001. Dicas para a realização de provas e concursos artigo por artigo. Salvador: PODIVM, 2011.

LUCENA, Eliana. Lacunas fazem a Funai reavaliar Estatuto do Índio. O Estado de São Paulo, São Paulo, 20 fev. 1977. Geral, p. 18. Disponível em: https://documentacao. 
socioambiental.org/noticias/anexo_noticia/35944_20160525_102126.pdf. Acesso em: 14 nov. 2019.

MARCZYNSKI, Solange Rita. Índios: temas polêmicos. Revista de Informação Legislativa, Brasília, ano 28, n. 111, p. 321-34, jul./set. 1991.

MARTINS, Tatiana Azambuja Ujacow. Direito ao pão novo: o princípio da dignidade humana e a efetivação do direito indígena. São Paulo, Pillares, 2005.

MENEZES, Gustavo Hamilton de Souza. O conceito de aculturação indígena na Antropologia e na esfera jurídica. In: MELO, Juliana; SIMIÃO, Daniel; BAINES, Stephen (Org.). Ensaios sobre justiça, reconhecimento e criminalidade. Natal, RN: EDUFRN, 2016. p. 519-39.

MINISTRO prepara visita de Geisel aos "Terena". Folha de São Paulo, São Paulo, 16 mar. 1977. Nacional, p. 10.

MOREIRA, Memélia. Fonseca presidirá Funai, índios terão cargos de chefia. Folha de São Paulo, São Paulo, 9 maio 1984. Política, p. 7.

OLIVEIRA, Jair de. Depoimento fornecido na 15a reunião da Comissão Parlamentar de Inquérito sobre Reservas Indígenas, realizada em 01/09/1977. Diário do Congresso Nacional (Seção 1) - Suplemento ao n. 72. Brasília, 17 de junho de 1978. p. 167-88.

O QUE se deve prever na emancipação do índio. O Estado de São Paulo, São Paulo, 24 mar. 1978. Notas e informações, p. 3.

ORGANIZAÇÃO INTERNACIONAL DO TRABALHO - OIT. Convenção n. 107. Concernente à proteção e integração das populações indígenas e outras populações tribais e semitribais de países independentes. Genebra, 5 de junho de 1957. Disponível em: http://www.trtsp. jus.br/geral/tribunal2/LEGIS/CLT/OIT/OIT_107.html. Acesso em: 28 set. 2018.

PACHECO DE OLIVEIRA, João. Sem tutela, uma nova moldura de nação. O pós-constituição de 1988 e os povos indígenas. Brasiliana - Journal for Brazilian Studies, Londres, v. 5, n. 1, p. 200-229, nov. 2016.

PACHECO DE OLIVEIRA, João. Políticas indígenas contemporáneas: régimen tutelar, juegos políticos y estratégias indígenas. In: PACHECO DE OLIVEIRA, João (Org.). Hacia una Antropologia del indigenismo. Rio de Janeiro: Contracapa, 2006. p. 127-50.

PACHECO DE OLIVEIRA, João; FREIRE, Carlos Augusto da Rocha. A presença indígena na formação do Brasil. Brasília: MEC/SECAD; LACED/Museu Nacional, 2006. 
PEREIRA, Levi Marques. Os Terena de Buriti: formas organizacionais, territorialização e representação da identidade étnica. Dourados, MS: Editora da UFGD, 2009.

RAMOS, Alcida Rita. O pluralismo brasileiro na berlinda. Etnográfica, Lisboa, v. 8, n. 2, p. 165-83, 2004.

RAMOS, Alcida Rita. O índio hiper-real. Revista Brasileira de Ciências Sociais, São Paulo, v. 28, n. 10, p. 5-14, 1995.

RAMOS, Alcida Rita. Vozes indígenas: o contato vivido e contado. Anuário Antropológico/87. Brasília: Editora da Universidade de Brasília; Rio de Janeiro: Tempo Brasileiro, 1990. p. 117-43.

RAMOS, Alcida Rita. Os direitos humanos dos povos indígenas no Brasil. In: MAYBURYLEWIS, Biorn; RANINCHESKI, Sonia (Org.). Desafios aos direitos humanos no Brasil contemporâneo. Brasília: CAPES/Verbena, 2011. p. 65-87.

RANGEL enviará à FUNAI projeto que emancipa os índios. O Progresso, Dourados, MS, 11/12 jan. 1978. p. 1.

REIS, Maurício Rangel. A ação do Ministério do Interior e o desenvolvimento nacional. Brasília: MINTER, 1978.

ROCHA, Everardo. Jogos de espelho: ensaios de cultura brasileira. Rio de Janeiro: Mauad, 2003.

RIBEIRO, Darcy. Os índios e a civilização: a integração das populações indígenas no Brasil moderno. Petrópolis, RJ: Vozes, 1986.

SANT'ANA, Graziella Reis de. História, espaços, ações e símbolos das associações indígenas Terena. 2010. Tese (Doutorado em Ciências Sociais) - Instituto de Filosofia e Ciências Humanas, Universidade Estadual de Campinas, Campinas, SP, 2010.

SANTOS, Sílvio Coelho dos. Os direitos dos indígenas no Brasil. In: LOPES DA SILVA, Aracy; GRUPIONI, Luís Donisete Benzi (Org.). A temática indígena na escola: novos subsídios para professores de 1ํ e 2o graus. Brasília: MEC, 1995. p. 87-105.

SCHADEN, Egon. Aculturação indígena. São Paulo: Ed. da USP, 1969.

SEM explicação, FUNAl pune Terena... Folha de São Paulo, Nacional, p. 6. São Paulo, 12 ago. 1981. 
TERENA, Marcos. Posso ser o que vocêé, sem deixar de ser quem sou! In: RAMOS, Marise Nogueira; ADÃO, Jorge Manoel; BARROS, Graciete Maria Nascimento (Coord.). Diversidade na educação: reflexões e experiências. Brasília: MEC, 2003. p. 99-109.

TERENA, Marcos. Vôo de índio. Terra Indígena, Araraquara, SP, n. 55, p. 5-9, abr./jun. 1990.

TERENA, Marcos. O índio exige respeito. Veja, São Paulo, Editora Abril, n. 649, 11 fev.1981. p. 90.

TRF mantém os terenas em Brasília. O Estado de São Paulo, São Paulo, 26 jun. 1981. Geral, p. 13.

TRINIDAD, Carlos Benítez. A questão indígena sob a ditadura militar: do imaginar ao dominar. Anuário Antropológico, Brasília, v. 43, n. 1, p. 257-84, 2018.

VARGAS, Vera Lúcia Ferreira. O SPI sob a perspectiva Terena. In: FREIRE, Carlos Augusto da Rocha (Org.). Memória do SPI: textos, imagens e documentos sobre o Serviço de Proteção aos Índios (1910-1967). Rio de Janeiro: Museu do Índio/FUNAI, 2011. p. 383-7.

XIMENES, Lenir Gomes. Terra Indígena Buriti: estratégias e performances terena na luta pela terra. 2011. Dissertação (Mestrado em História) - Universidade Federal da Grande Dourados, Dourados, MS, 2011.

\section{Sobre o autor:}

Victor Ferri Mauro: Doutor em História pela Universidade Federal da Grande Dourados (UFGD). Professor adjunto da Universidade Federal de Mato Grosso do Sul (UFMS). E-mail: victorfmauro@gmail.com, Orcid: https://orcid.org/0000-0003-1276-4684

Recebido em 14 de novembro de 2018

Aprovado para publicação em 13 de março de 2019 